\title{
Precipitate Behavior in Fe-20Cr-30Ni-2Nb Austenitic Heat-Resistant Steel
}

\author{
Hiroki Ishikawa $\cdot$ Chi Zhang $\cdot$ Sheng-Wei Chen $\cdot$ Zhi-Gang Yang
}

Received: 9 April 2014/Revised: 11 December 2014/Published online: 20 January 2015

(C) The Chinese Society for Metals and Springer-Verlag Berlin Heidelberg 2015

\begin{abstract}
In this study, the precipitation behavior of a new austenitic heat-resistant steel $(\mathrm{Fe}-20 \mathrm{Cr}-30 \mathrm{Ni}-2 \mathrm{Nb}$, in at $\%)$ was investigated. The effects of alloying addition of boron (B) and lanthanum (La) on the microstructure of the austenitic steel were scrutinized using SEM, EPMA, TEM, and XRD. The results showed that the addition of B enhanced the precipitation of bar-type Laves phase. A small precipitate with high La concentration was observed at the grain boundary in the alloy without aging; similar precipitates without La also presented in region adjacent to the La single phase. This result indicates that La can exist independently and does not contribute to the formation of new compounds. However, in both Band La-modified alloy, B appeared in the precipitate free zone. In the alloy containing both $\mathrm{B}$ and $\mathrm{La}$, only $\mathrm{Fe}_{2} \mathrm{Nb}$ Lavesphase precipitates, as indicated by the XRD result.
\end{abstract}

KEY WORDS: Precipitation free zone; Grain boundary; Phase transformation; Microstructure; Fe-20Cr-30Ni-2Nb austenitic heat-resistant steel

\section{Introduction}

Coal-fired thermal power plants, operating at high efficiency, are prerequisites for saving resources and energy. Present austenitic steels are capable of operating at temperature higher than $700{ }^{\circ} \mathrm{C}$ [1-6]. However, commercial heat-resistant austenitic steels suffer from low creep rupture strengths at such high temperatures. The low creep strength is associated with the carbides/nitrides in

Available online at http://link.springer.com/journal/40195

H. Ishikawa $\cdot$ C. Zhang $\cdot$ S.-W. Chen · Z.-G. Yang

School of Materials Science and Engineering, Tsinghua

University, Beijing 100084, China

H. Ishikawa ( $\square)$

Department of Chemistry and Materials Science, Tokyo Institute of Technology, Meguro-Ku, Tokyo 152-8552, Japan

e-mail: hiroki.i.ab@m.titech.ac.jp the microstructure, which coarsen during a long-time service [7]. In austenitic stainless steels, carbides at the grain boundaries provide preferential sites for cavity nucleation under creep-fatigue interaction conditions, thereby drastically reducing the creep-fatigue life $[2,8$, 9]. Creep strength is the most important mechanical properties at high-temperature services [7]. Takeyama et al. [3] proposed a new type of austenitic heat-resistant steel of $\mathrm{Fe}-20 \mathrm{Cr}-30 \mathrm{Ni}-2 \mathrm{Nb}$ (at\%), which is strengthened by the thermodynamically stable intermetallic phases of $\mathrm{Fe}_{2} \mathrm{Nb}$ TCP (topologically close-packed) phase [3, 1012]. In the Laves phase, a high thermal stability of $\mathrm{Fe}_{2} \mathrm{Nb}$ particle distribution within the $\gamma$-Fe matrix was observed in the alloys with small additions of B [3] during creep testing at around $800{ }^{\circ} \mathrm{C}$. La addition is known to refine the grain boundaries in steels, but few researches had focused on the possible effect of La doping to the grain boundaries [13-15].

The objective of this work is to investigate the effect of heat treatment, adding alloy elements such as $\mathrm{B}$ and $\mathrm{La}$ on the microstructure of $\mathrm{Fe}-20 \mathrm{Cr}-30 \mathrm{Ni}-2 \mathrm{Nb}$. 


\section{Experimental}

Four alloys of different compositions were prepared, as confirmed by XRF and summarized in Table 1. Alloys were melted from commercially pure metals and dropcasted to make bar ingots with a size of $15 \mathrm{~mm} \times 15 \mathrm{~mm} \times 150 \mathrm{~mm}$. Alloys were cut into pieces of small cubes of $10 \mathrm{~mm} \times 10 \mathrm{~mm} \times 15 \mathrm{~mm}$ and homogenized at $1,150{ }^{\circ} \mathrm{C}$ for $72 \mathrm{~h}$ in vacuum. Then, all the samples were kept at $1,150^{\circ} \mathrm{C}$ for $20 \mathrm{~min}$ followed by $800{ }^{\circ} \mathrm{C}$ for $12 \mathrm{~h}$ and quenched in water finally.

Metallographic samples for SEM and EPMA were prepared by grinding the samples using SiC papers until 2000 grit and polishing using $0.1 \mathrm{~mm}$ alumina powder and colloidal silica. The as-polished samples were etched in a solution containing $30 \mathrm{~mL} \mathrm{HCl}$ and $10 \mathrm{~mL} \mathrm{HNO}_{3}$ for $10 \mathrm{~s}$ at room temperature. Microstructures of the alloys were examined using a field emission scanning electron microscope (FE-SEM) and transmission electron microscopy (TEM). Phase compositions were analyzed with electronprobe microanalyzer (EPMA). Samples for TEM were prepared by conventional twin-jet electro-polishing using a solution of methanol/perchloric acid with a condition at $-20{ }^{\circ} \mathrm{C}$ and $60 \mathrm{~V}$ for $2 \mathrm{~min}$. Present phases were observed using selected area diffraction patterns (SADP), and phase identification was done by X-ray diffraction (XRD) using $\mathrm{Cu} K_{\alpha}$ radiation. Commercial Thermo-Calc software with database SSOL5 was used to calculate the microstructure and identify the possible precipitate phase.

\section{Results and Discussion}

\subsection{Microstructural Evolution}

Figure 1 shows the SEM images of the base alloy and alloys with La and B additions. Bar-type and block-type precipitates can be found at the grain boundaries in all alloys. The thickness of bar-type precipitates is approximated as $0.5 \mu \mathrm{m}$, and the diagonal of block-type precipitates is $4 \mu \mathrm{m}$. Comparing Fig. 1a, b, the addition of B to base alloy increased the line density of precipitation along grain boundary, while doping La did not make large difference about it. Dense generated precipitation in bothmodified alloy is also because of boron. Tarigan et al. [3] reported that higher density is attributed to better creep rupture strength.

\subsection{XRD Analysis}

The phase equilibrium of the four alloys at $800{ }^{\circ} \mathrm{C}$ was calculated using Thermo-Calc and database SSOL5, and the results are shown in Table 2. In all alloys, $\gamma$-phase
Table 1 Compositions of the experimental alloys (wt $\%$ )

\begin{tabular}{llllllll}
\hline Alloy & $\mathrm{Cr}$ & $\mathrm{Ni}$ & $\mathrm{Nb}$ & $\mathrm{B}$ & $\mathrm{La}$ & $\mathrm{C}$ & $\mathrm{Fe}$ \\
\hline Base alloy & 18.35 & 31.07 & 3.28 & & & $<0.01$ & $\mathrm{Bal}$. \\
B-modified & 18.35 & 31.08 & 3.28 & 0.01 & & $<0.01$ & $\mathrm{Bal}$ \\
La-modified & 18.30 & 30.98 & 3.27 & & 0.49 & $<0.01$ & $\mathrm{Bal}$ \\
Both-modified & 18.30 & 30.99 & 3.27 & 0.01 & 0.49 & $<0.01$ & $\mathrm{Bal}$ \\
\hline
\end{tabular}

(austenite) is the largest proportion ( $>90 \%)$ of the present phases. Base alloy and $\mathrm{B}$-modified alloy contained $\mathrm{NbNi}_{3}$, whereas La-modified alloy showed $\mathrm{LaNi}_{3}$ phase. Moreover, a small amount of $\mathrm{Cr}_{5} \mathrm{~B}_{3}$ appeared in B-modified alloy, and $\mathrm{FeB}$ showed up in alloys modified with both $\mathrm{La}$ and $\mathrm{B}$. The calculated phases were confirmed using XRD for four studied alloys although $\mathrm{Fe}_{2} \mathrm{Nb}$ is observed in both base alloy and B-modified alloy, as reported elsewhere [3, 16]. Further work is needed to explore this result.

Figure 2 shows the XRD spectrum of the alloys in $2 \theta$ range of $34^{\circ}-49^{\circ}$. Stronger peaks indicate austenite at $43.6^{\circ}$. Moreover, noticeable small peaks represent other remarkable compounds in the microstructure. The results are different from phase calculation using Thermo-Calc: Phases such as $\mathrm{NbNi}_{3}$ and $\mathrm{LaNi}_{3} \mathrm{FeB}$ did not appear in XRD spectra. Three phases were identified from the smaller peaks: $\mathrm{NbC}$ at $34.7^{\circ}$ and $40.3^{\circ}$ in the base alloy, $\mathrm{Fe}_{3} \mathrm{Nb}_{3} \mathrm{C}$ at $37.2^{\circ}, 44.8^{\circ}$, and $\mathrm{Fe}_{2} \mathrm{Nb}$ at $39.1^{\circ}$ and $41.6^{\circ}$. No La- or B-based phase was detected by XRD although literature suggests transformation of $\mathrm{NbC}$ to $\mathrm{Fe}_{3} \mathrm{Nb}_{3} \mathrm{C}$ by $\mathrm{B}$ and La additions [17], as shown in Fig. 2 with the disappearance of $\mathrm{NbC}$ peak with $\mathrm{B}$ and La additions. It has been reported [18] that $\mathrm{Fe}_{3} \mathrm{Nb}_{3} \mathrm{C}$ can improve high-temperature strength of ferritic stainless, although the present alloy is austenitic, and henceforth, this is merely a speculation if this phase could increase the alloy strength. The alloy with both $\mathrm{La}$ and $\mathrm{B}$ additions show only $\mathrm{Fe}_{2} \mathrm{Nb}$ peak with austenite peak, and other two peaks remain absent. $\mathrm{Fe}_{2} \mathrm{Nb}$ has been reported as to increase the creep strength $[3,10,11$, 16]. Therefore, alloy doped with both $\mathrm{B}$ and $\mathrm{La}$ is promising alloy with improved mechanical properties at higher temperature service conditions.

\subsection{Microstructure and Phase Composition}

\subsection{1 $\mathrm{Fe}-20 \mathrm{Cr}-30 \mathrm{Ni}-2 \mathrm{Nb}$}

Figure 3 shows the element distributions of a precipitate along the grain boundary of $\mathrm{Fe}-20 \mathrm{Cr}-30 \mathrm{Ni}-2 \mathrm{Nb}$ alloy. From Fig. 3, it can be concluded that this is a precipitate mainly containing $\mathrm{C}$ and $\mathrm{Nb}$. Moreover, the amounts of other elements like $\mathrm{Fe}, \mathrm{Ni}$, and $\mathrm{Cr}$ in the precipitate are much less than those in matrix. 

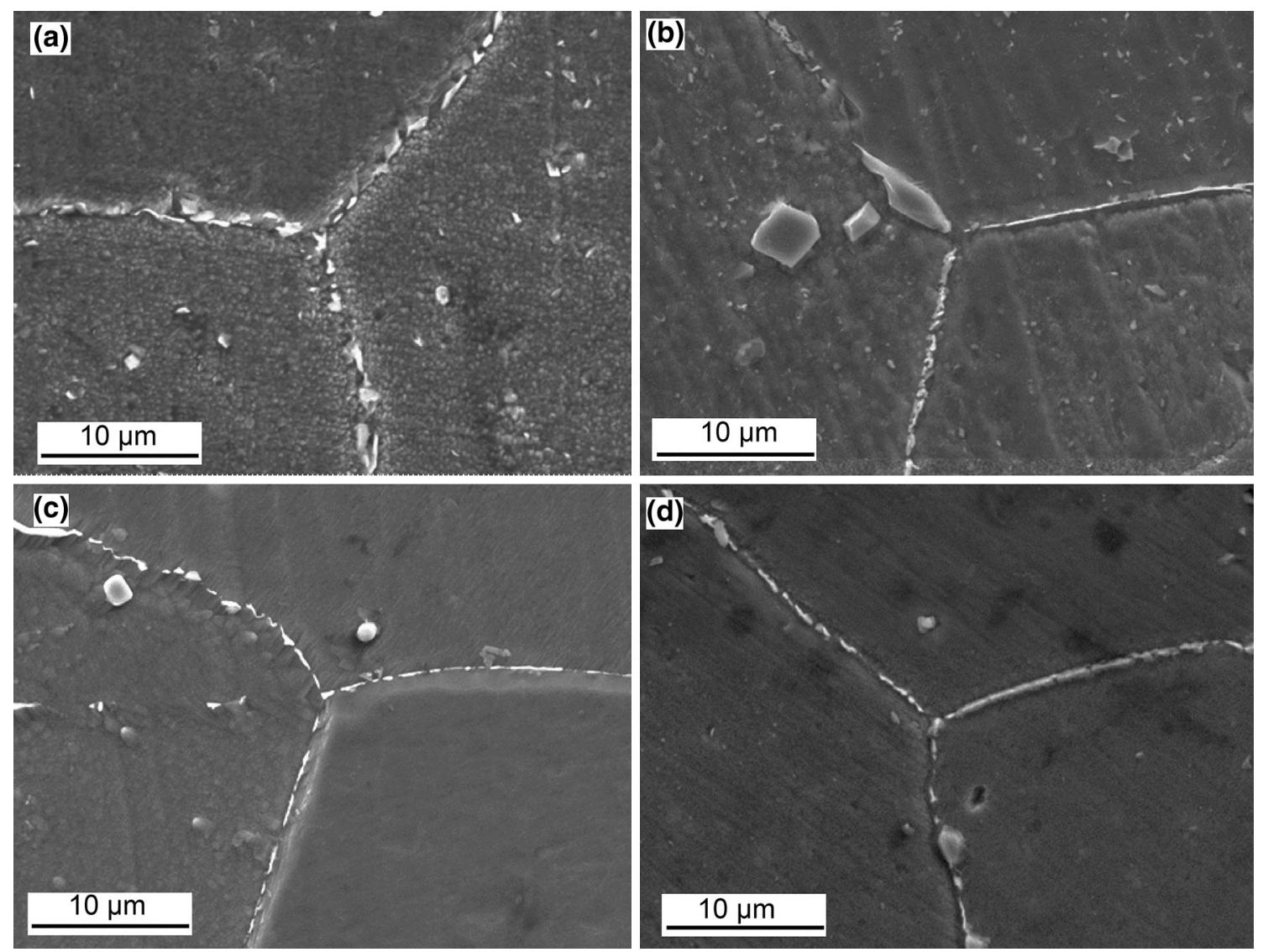

Fig. 1 SEM images of different alloys after heat treated at $1,150{ }^{\circ} \mathrm{C}$ for $20 \mathrm{~min}$ and then at $800{ }^{\circ} \mathrm{C}$ for $12 \mathrm{~h}$ followed water quenching: a base alloy; b B-modified alloy; c La-modified alloy; d B and La co-modified alloy

Table 2 Calculated results of the phase amount for different alloys $(\mathrm{mol} \%)$

\begin{tabular}{llllll}
\hline Alloy & fcc matrix & $\mathrm{NbNi}_{3}$ & $\mathrm{LaNi}_{3}$ & $\mathrm{Cr}_{5} \mathrm{~B}_{3}$ & $\mathrm{FeB}$ \\
\hline Base alloy & 92.5 & 7.41 & - & - & - \\
B-modified & 92.6 & 7.00 & - & 0.14 & - \\
La-modified & 99.1 & - & 0.80 & - & - \\
Both-modified & 99.1 & - & 0.80 & - & 0.05 \\
\hline
\end{tabular}

Figure 4 shows the TEM images of the precipitate at the grain boundary of base alloy, $\mathrm{Fe}_{2} \mathrm{Nb}$ phase in grain, and its diffraction pattern. $\mathrm{Fe}_{2} \mathrm{Nb}$ Laves phase is identified in grain, as indicated by the diffraction pattern. Even though there is no clear diffraction pattern of precipitates at the grain boundary was obtained, the EPMA results (see Fig. 3) suggest this phase should be $\mathrm{NbC}$.

\subsection{2 $\mathrm{Fe}-20 \mathrm{Cr}-30 \mathrm{Ni}-2 \mathrm{Nb}-0.03 \mathrm{~B}$}

Figure 5 shows the TEM images of the precipitates at the grain boundary of $\mathrm{B}$-modified alloy, $\mathrm{Fe}_{2} \mathrm{Nb}$ phase in grain,

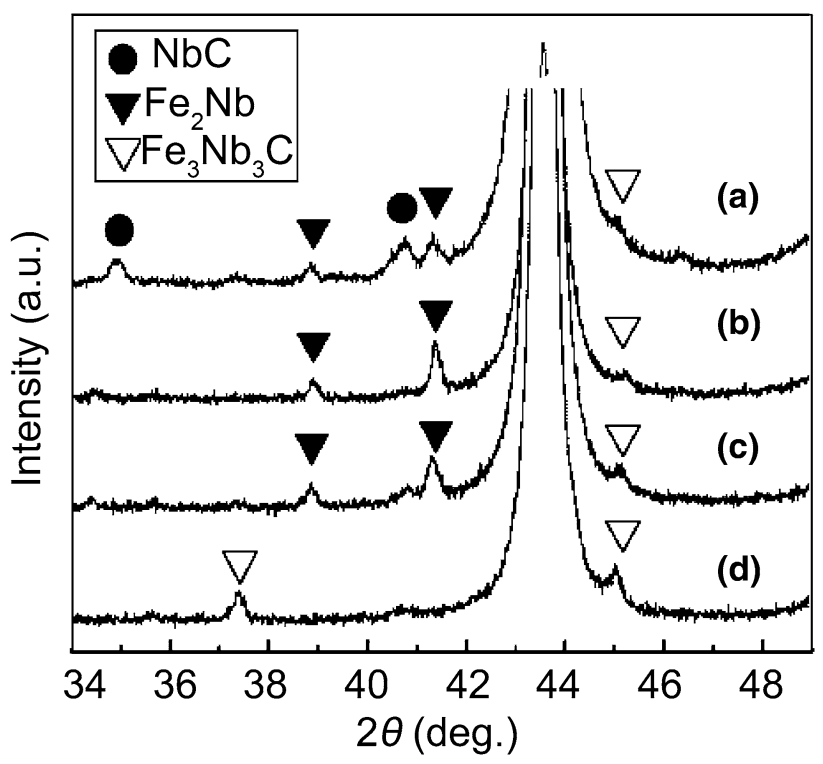

Fig. $2 \mathrm{XRD}$ patterns in the $2 \theta$ range from $34^{\circ}$ to $49^{\circ}$ of different alloys: a base alloy; $\mathbf{b}$ B-modified alloy; $\mathbf{c}$ La-modified alloy; $\mathbf{d}$ B and La co-modified alloy 

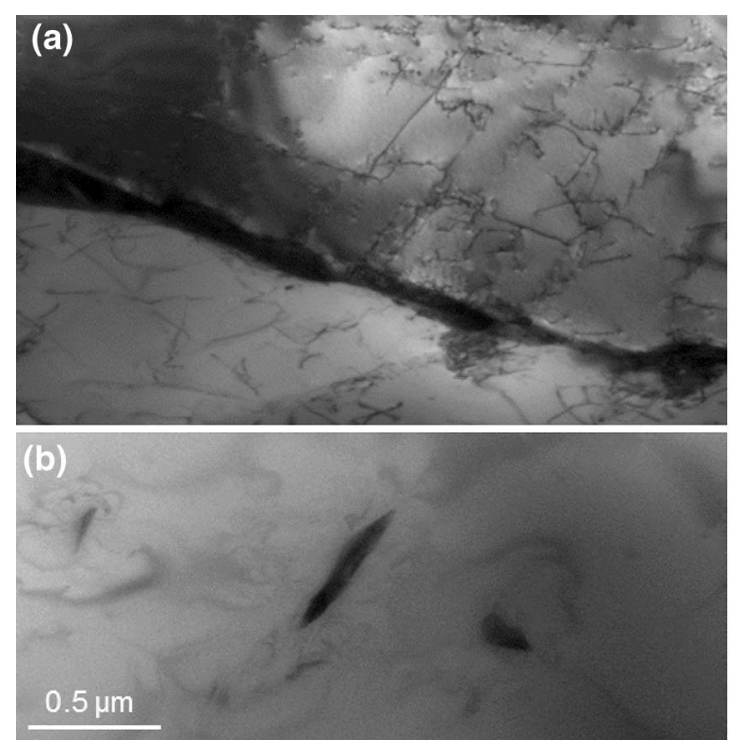

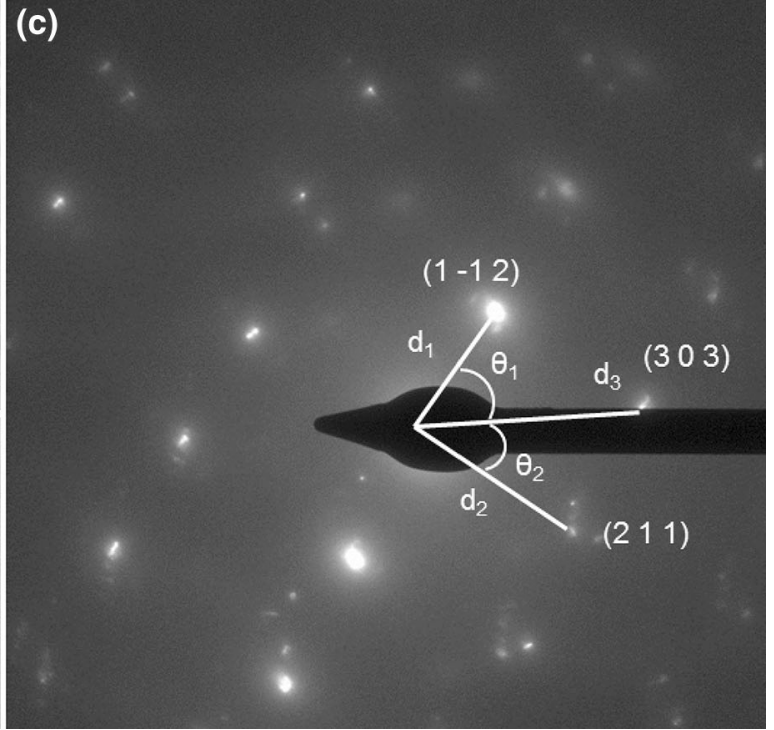

Fig. 4 TEM images of the base alloy showing the precipitate on grain boundary $\mathbf{a} ; \mathrm{Fe}_{2} \mathrm{Nb}$ phase in grain $\mathbf{b}$; diffraction pattern of $\mathrm{Fe}{ }_{2} \mathrm{Nb} \mathbf{c}$
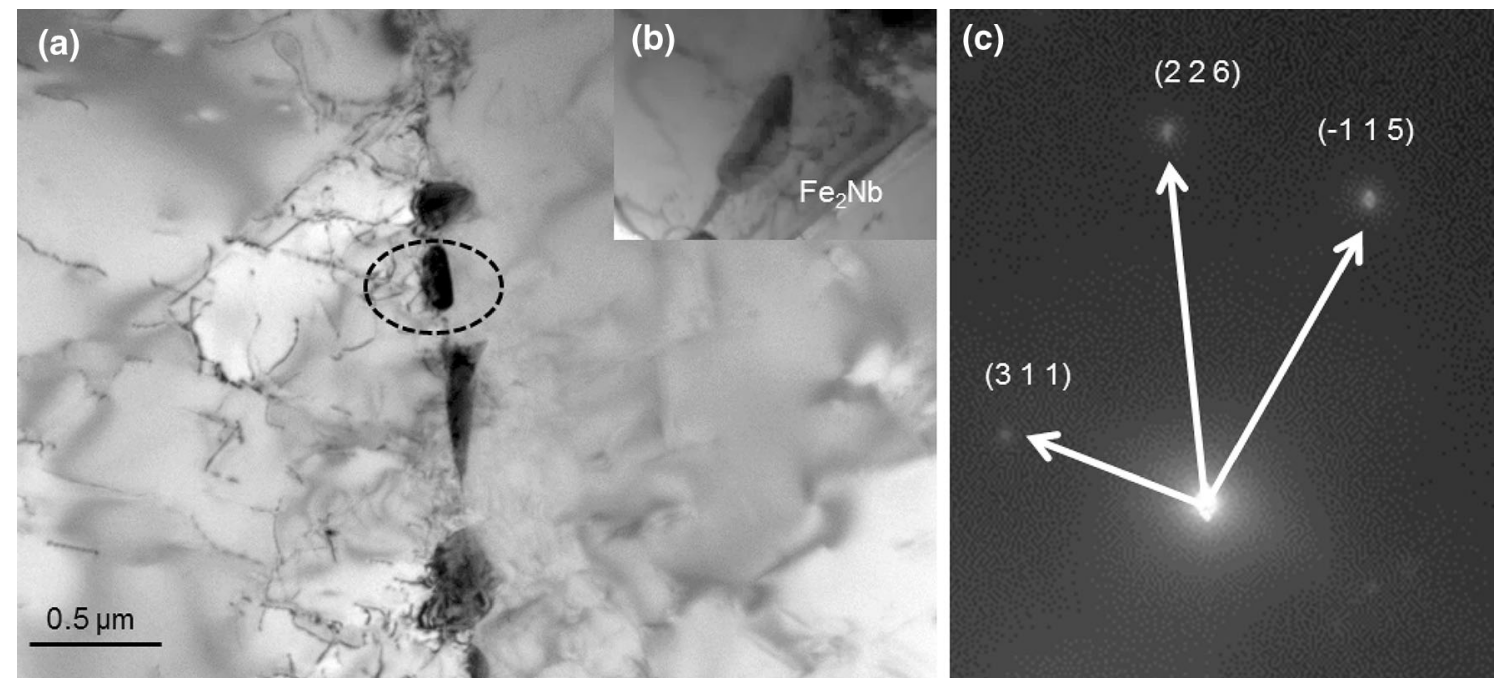

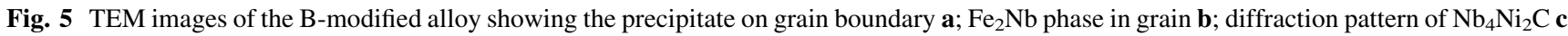

and the diffraction pattern of $\mathrm{Nb}_{4} \mathrm{Ni}_{2} \mathrm{C}$. $\mathrm{Fe}_{2} \mathrm{Nb}$ in $\mathrm{B}$-modified alloy was generated in grain, and then, it is in line with the result of base alloy. It was reported that the strength increase is obtained by the addition of B into low carbon steel $[3,19]$. However, carbon seems to help form other compound like $\mathrm{Nb}_{4} \mathrm{Ni}_{2} \mathrm{C}$. It may reduce creep resistance, because $M_{6} \mathrm{C}$ carbide precipitates and coarsens rapidly above $900{ }^{\circ} \mathrm{C}[20]$.

\subsection{3 $\mathrm{Fe}-2 \mathrm{OCr}-30 \mathrm{Ni}-2 \mathrm{Nb}-0.2 \mathrm{La}$}

Figure 6 shows the EPMA result of La-modified alloy. There is one circle precipitation on grain boundary. It has high $\mathrm{La}$ concentration, but La does not exist outside even though bartype precipitation is above it. Adding La does not affect other precipitation, contrary to expectation which refines grain boundary $[13,15]$. Figure 7 shows the TEM images of precipitation grain boundary in La-modified alloy. $\mathrm{Nb}_{4} \mathrm{Ni}_{2} \mathrm{C}$ was observed like it in the B-modified alloy (Fig. 5). The EPMA data show that single La phase does not affect the precipitation on grain boundary, though it facilitates formation of $\mathrm{Nb}_{4} \mathrm{Ni}_{2} \mathrm{C}$, which did not appear in the base alloy. $\mathrm{B}$-modified and La-modified alloys have similar XRD peaks, so the addition of alloy elements may affect generating mechanism.

\subsubsection{Fe-20Cr-30Ni-2Nb-0.03B-0.2La}

Figure 8 shows the EPMA results of precipitation on grain boundary in B and La co-modified alloy after 12-h 

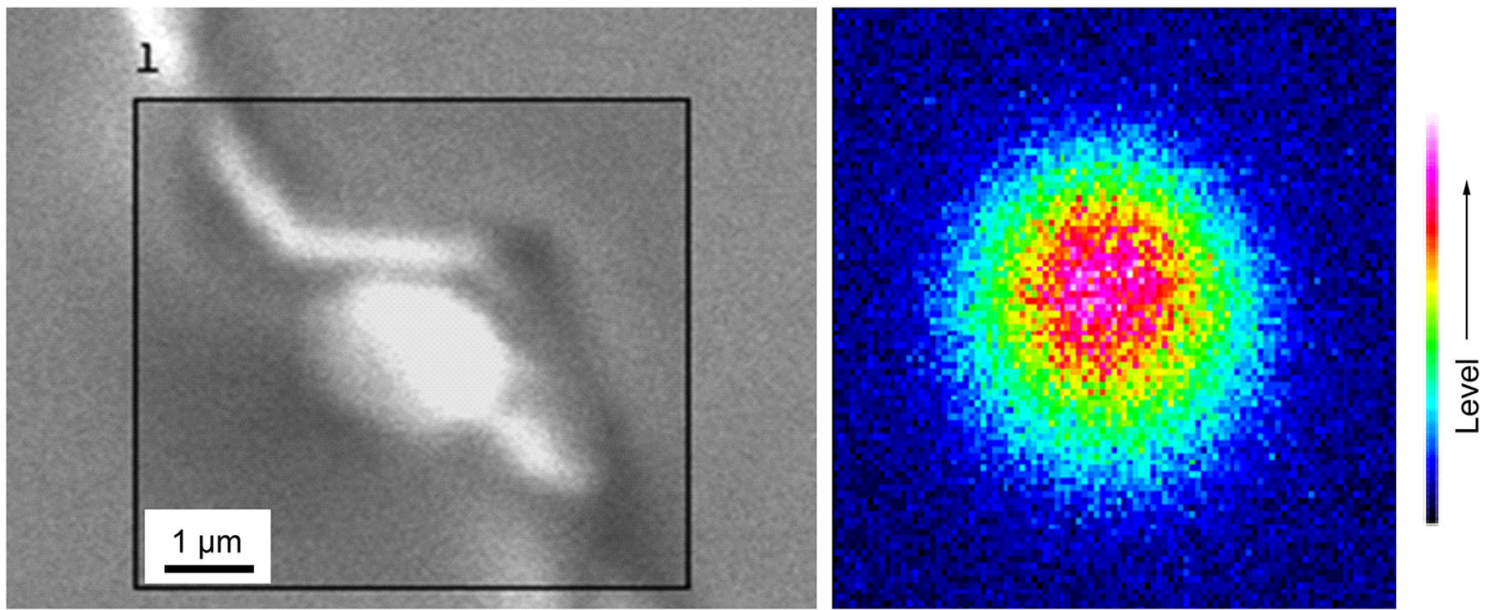

Fig. 6 SEM image a; EPMA result of La $\mathbf{b}$ of a precipitate in heat-treated La-modified alloy
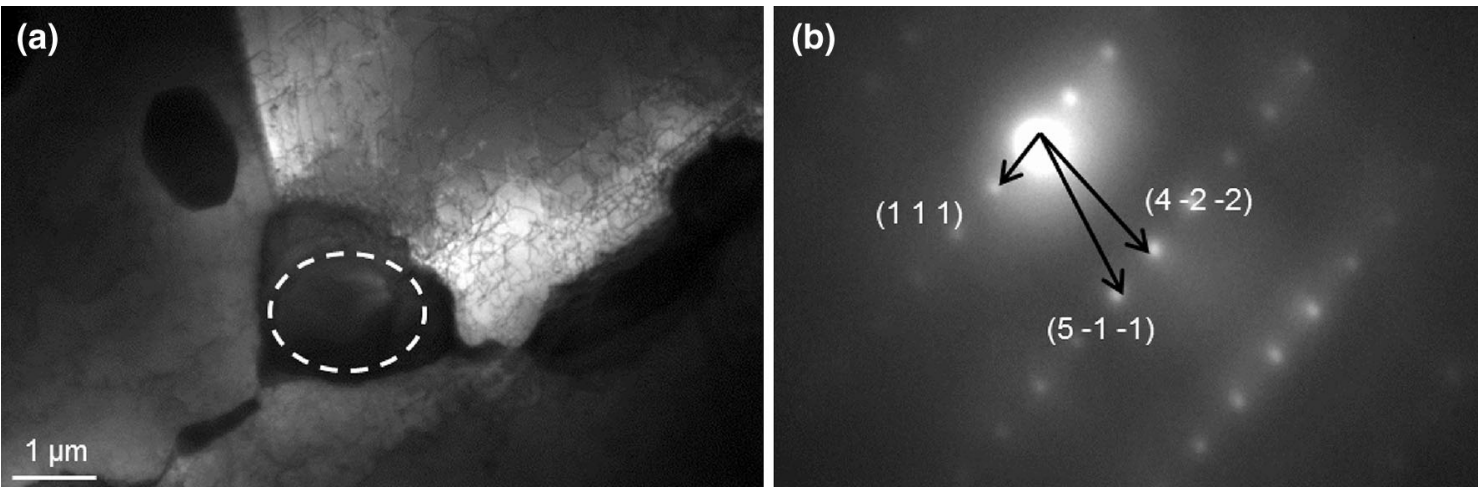

Fig. 7 TEM image of a precipitate on grain boundary in La-modified alloy a; the diffraction pattern of $\mathrm{Nb}_{4} \mathrm{Ni}_{2} \mathrm{C} \mathbf{b}$
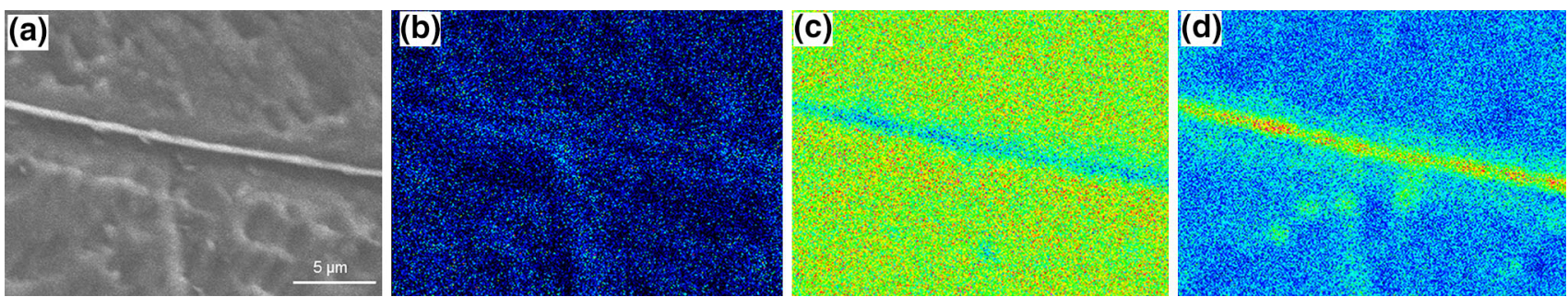

Fig. 8 SEM image a; EPMA results of elements B b; Fe c; Nb d for heat-treated B and La co-modified alloy

aging. It can be found that $\mathrm{B}$ appears preferentially in precipitation free zone (PFZ); Fe concentration in matrix is higher than that in the precipitation, while $\mathrm{Nb}$ is richer in precipitation. The spots, where $\mathrm{B}$ is generated, is noticeable because PFZ often forms in many alloys, suggesting that the nucleation of precipitates is affected to some extent in the vicinity of grain boundaries [21, 22]. This effect should be researched more, in order to check its mechanical property. However, it may result in the formation of a compound except for $\mathrm{B}$ on the grain boundary [10]. Figure 9 shows the TEM image and the diffraction pattern of precipitation on grain boundary in B and $\mathrm{La}$ co-modified alloy. From Fig. 9, only $\mathrm{Fe}_{2} \mathrm{Nb}$ was observed. As mentioned before, XRD peaks of $\mathrm{B}$ and $\mathrm{La}$ co-modified alloy indicate austenite and $\mathrm{Fe}_{2} \mathrm{Nb}$. It does not seem that the alloy has other precipitation, which means doping $\mathrm{B}$ and $\mathrm{La}$ enhances generation of $\mathrm{Fe}_{2} \mathrm{Nb}$ on grain boundary, though the mechanism remains unclear.

\section{Conclusions}

(1) Two types of precipitates, brock shape and bar shape appeared and increased line density in grain by the 

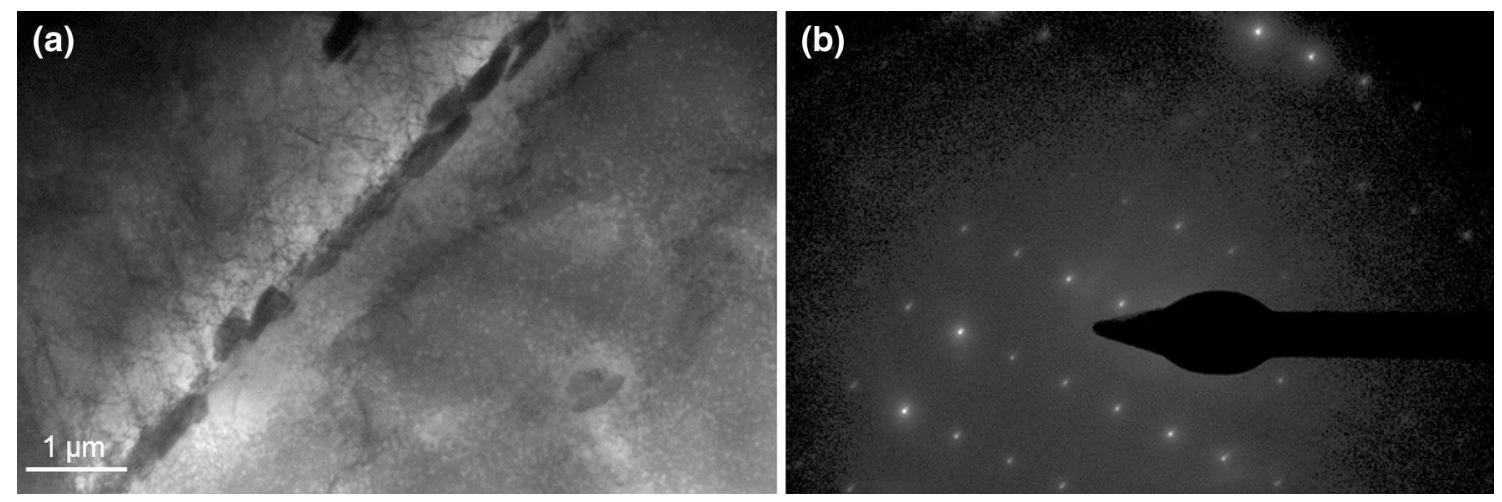

Fig. 9 TEM image of the $\mathrm{Fe}_{2} \mathrm{Nb}$ precipitates on grain boundary in $\mathrm{B}$ and La co-modified alloy $\mathbf{a}$; diffraction pattern of $\mathrm{Fe}_{2} \mathrm{Nb} \mathbf{b}$

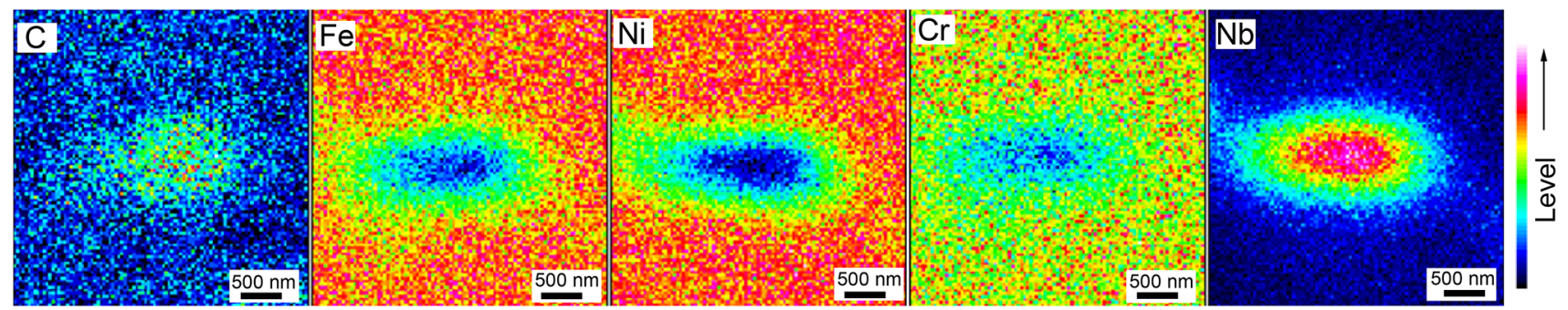

Fig. 3 EPMA results of $\mathrm{C}, \mathrm{Fe}, \mathrm{Ni}, \mathrm{Cr}$, and $\mathrm{Nb}$ for a precipitate along the grain boundary in $\mathrm{Fe}-20 \mathrm{Cr}-30 \mathrm{Ni}-2 \mathrm{Nb}$ alloy

addition of $\mathrm{B}$ into $\mathrm{Fe}-20 \mathrm{Cr}-30 \mathrm{Ni}-2 \mathrm{Nb}$ alloy. However, the addition of La did not lead to the increase in line density.

(2) $\mathrm{NbC}, \mathrm{Fe}_{3} \mathrm{Nb}_{3} \mathrm{C}$, and $\mathrm{Fe}_{2} \mathrm{Nb}$ Laves phases are observed in austenite matrix. $\mathrm{NbC}$ was found in base alloy, and the addition of $\mathrm{B}$ and $\mathrm{La}$ changes $\mathrm{NbC}$ to $\mathrm{Fe}_{3} \mathrm{Nb}_{3} \mathrm{C}$. Regardless of carbon, only small peaks of $\mathrm{Fe}_{2} \mathrm{Nb}$ were observed, except for a peak of matrix in bothmodified alloy, which means it may have higher concentration of $\mathrm{Fe}_{2} \mathrm{Nb}$ Laves phase.

(3) Unlike other elements, B appeared in the precipitation free zone, instead of precipitates along grain boundaries. In base alloy, $\mathrm{NbC}$ presents on grain boundary, and $\mathrm{Fe}_{2} \mathrm{Nb}$ shows up inside grains and on grain boundary. B-modified alloy had $\mathrm{Nb}_{4} \mathrm{Ni}_{2} \mathrm{C}$ on grain boundary and $\mathrm{Fe}_{2} \mathrm{Nb}$ in grain. La-modified alloy includes La single-phase precipitation on grain boundary. However, La was not contained in other precipitates like bar-shaped ones. Therefore, it exists independently and does not seem to help new precipitates to form.

\section{References}

[1] Y. Noguchi, H. Okada, H. Semba, M. Yoshizawa, Proc. Eng. 10, 1127 (2011)

[2] G. Chai, M. Boström, M. Olaison, U. Forsberg, Proc. Eng. 55, 232 (2013)
[3] I. Tarigan, K. Kurata, N. Takata, T. Matsuo, M. Takeyama, Mater. Res. Sci. Symp. Proc. 1295, 317 (2011)

[4] Z.H. Zhong, Y.F. Gu, Y. Yuan, Z. Shi, Mater. Lett. 109, 38 (2013)

[5] S.J. Patel, J.J. DeBarbadillo, B.A. Baker, R.D. Gollihue, Proc. Eng. 55, 246 (2013)

[6] T. Tokairin, K.V. Dahl, H.K. Danielsen, F.B. Grumsen, T. Sato, J. Hald, Mater. Sci. Eng. A 565, 285 (2013)

[7] I.S. ELMahallawi, Mater. Lett. 51, 375 (2001)

[8] K.S. Min, K.J. Kim, S.W. Nam, J. Alloys Compd. 370, 223 (2004)

[9] L.J. Wang, L.Y. Sheng, C.M. Hong, Mater. Des. 37, 349 (2012)

[10] Y. Yamamoto, M. Takeyama, Z.P. Lu, C.T. Liu, N.D. Evans, P.J. Maziasz, M.P. Brady, Intermetallics 16, 453 (2008)

[11] Y. Hasebe, K. Hashimoto, T. Matsuo, M. Takeyama, Mater. Res. Sci. Symp. Proc. 1295, 171 (2011)

[12] H.J. Kestenbach, L.O. Bueno, Mater. Sci. Eng. 66, 19 (1984)

[13] Q. Lin, F. Guo, X. Zhu, J. Rare Earths 25, 485 (2007)

[14] L. Wang, Q. Lin, J. Ji, D. Lan, J. Alloys Compd. 408, 384 (2006)

[15] M.J. Bennett, H.E. Bishop, P.R. Chalker, A.T. Tuson, Mater. Sci. Eng. 90, 177 (1987)

[16] S.W. Chen, C. Zhang, Z.X. Xia, H. Ishikawa, Z.G. Yang, Mater. Sci. Eng. A 616, 183 (2014)

[17] N. Fujita, H.K.D.H. Bhadeshia, M. Kikuchi, Model. Simu. Mater. Sci. Eng. 12, 273 (2004)

[18] N. Fujita, M. Kikuchi, K. Ohmura, ISIJ Int. 43, 1999 (2003)

[19] L.Y. Lan, C.L. Qiu, P. Zhou, D.W. Zhao, C.M. Li, X.H. Gao, L.X. Du, Acta Metall. Sin. (Engl. Lett.) 24, 473 (2011)

[20] N. Fujita, M. Kikuchi, H.K.D.H. Bhadeshia, Metall. Mater. Trans. A 33, 3339 (2002)

[21] S. Hossein Nedjad, M. Nili Ahmadabadi, T. Furuhara, Mater. Sci. Eng. A 490, 105 (2008)

[22] T. Ogura, S. Hirosawa, T. Sato, Sci. Technol. Adv. Mater. 5, 491 (2004) 